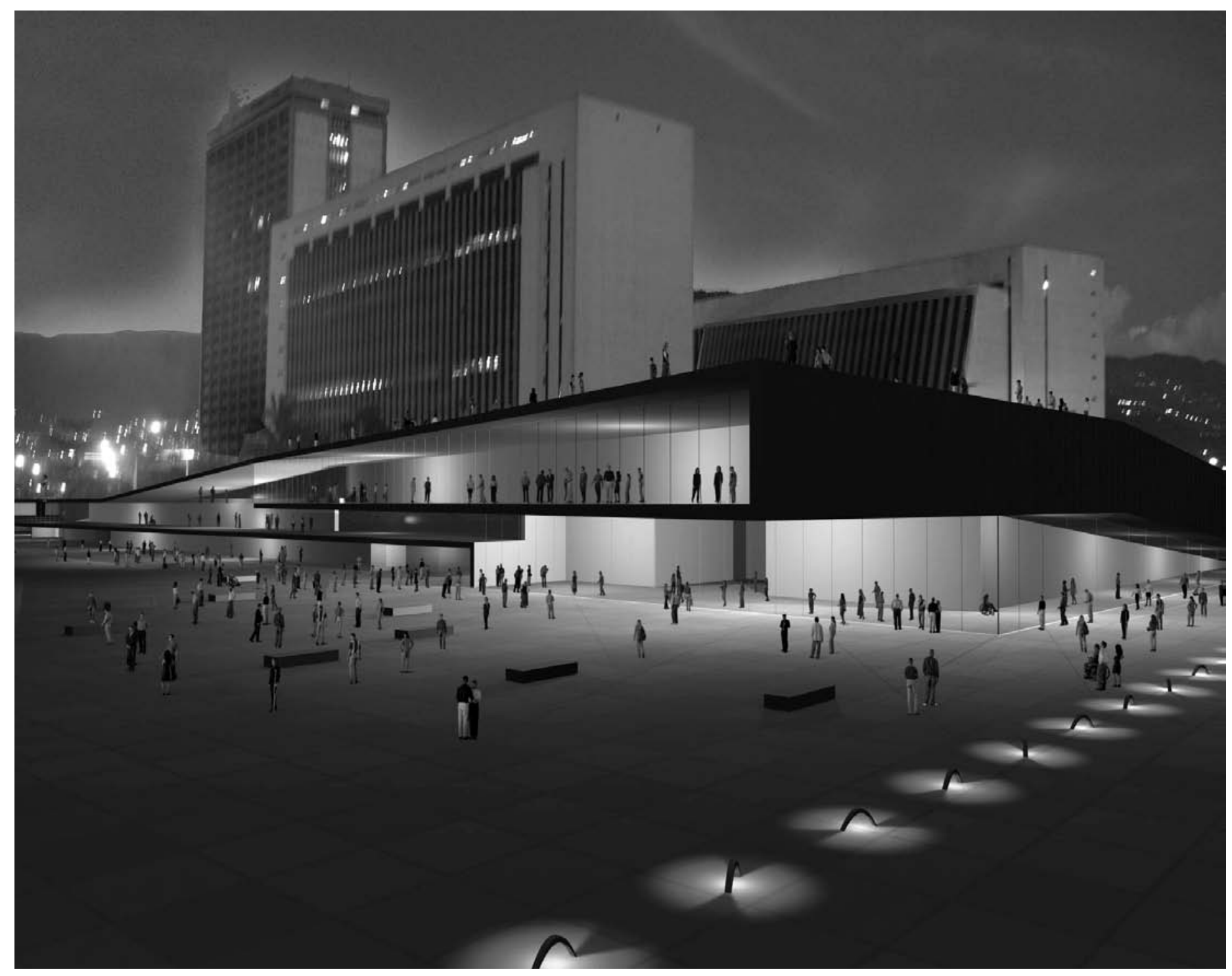

\title{
Tres hipótesis: un proyecto
}

Arq. Felipe Uribe de Bedout

Docente invitado FADU/UNL 
Hemos tenido recientemente la posibilidad de conocer personalmente las obras de Felipe Uribe de Bedout y confirmar lo que tuvimos la fortuna de escuchar (Ios pocos que asistimos la primera vez en noviembre de 2006 y los muchos en la segunda, en abril de 2007) su apasionado discurso sobre la arquitectura, la tipología, la obra, la técnica, los materiales, el espacio y la obra pública, el rol del estado y el proceso de diseño «no creo en la tipología como punto de partida en la arquitectura...»

Para Felipe, pensar-proyectar-construir-re pensar son caminos de ida y vuelta en la producción del objeto, «para mi la arquitectura es un proceso de reflexión».

Su dedicación y obstinación se perciben, la composición del plano de piso (siempre en tres dimensiones), los materiales, las texturas, el equipamiento, que enriquecen la mirada rasante desde la superficie, la apropiación táctil, el descanso y el atisbo lejano, en altura, desde el propio paisaje ondulado de Medellín y desde los edificios que completan los espacios.

El trabajo con las diferentes escalas: la cercana, personal, de juego y contemplación, la del grupo (la escala media) con la pérgola, el agua, la arena, las escalinatas donde se conversa y se aprende y el espacio para la multitud, otra vez para la contemplación, la educación y el ocio, el juego y la manifestación.

Impresiona la calidad constructiva, que manifiesta una dedicación y voluntad material poco frecuente (sobre todo en la obra pública). Lo pudimos escuchar contando como estudia las juntas de las piedras del piso, el pulido de las piezas, el detalle de los escurrimientos del agua.

Al mismo tiempo desarrolla y pone en acto un discurso sobre el rol del estado como agente de integración social, de transformación de la ciudad.

Las muchas conversaciones que hemos compartido nos han permitido conocer sus procesos de negociación con el comitente, en donde es capaz de convencer al director de una escuela pública que estaba construyendo, de quitar todas las rejas existentes, a cambio de regalarle el proyecto de piscinas que acababa de presentar.

Santa Fe es una ciudad que lo acogió y a la cual regresa cada vez que puede, donde se sintió cómodo para realizar junto a alumnos y arquitectos de nuestra facultad una propuesta de su estudio para Panamá, invitándolos luego a visitar y trabajar en su estudio durante una temporada.

Esta experiencia y el trabajo de los primeros visitantes permitieron este año formalizar un convenio de pasantías entre nuestra facultad y su estudio.

En marzo de este año protagonizó el primer Taller Ciudad, organizado por la Facultad de Arquitectura Diseño y Urbanismo y la Secretaría de Planeamiento de la Municipalidad de Santa Fe, (con la coorganización el Colegio de Arquitectos, La Universidad Tecnológica y la Universidad Católica), en donde expuso la experiencia de transformación urbana de Medellín con sus obras y proyectos en ese sentido.

En ese marco se llevó adelante un taller de ideas en convenio entre la Municipalidad de la ciudad y un equipo de alumnos y egresados de la FADU (algunos de los cuales ya habían compartido experiencias de proyecto con él), la propuesta urbana para el Molino Marconetti y zona Puerto Santa Fe. Visitó Alto Verde y compartió la mesa con habitantes del lugar.

Muchos encuentros posteriores en estos dos años de conocernos, nos permitieron confirmar que su discurso público transparenta lo que manifiesta persona a persona, que la arquitectura ocupa todo su tiempo, que nunca deja de construir, que tiene la capacidad de ver la mitad del vaso lleno siempre y que los problemas son para él invariablemente oportunidades.

\section{Antioquia Visión 2020}

El proyecto Antioquia Visión 2020 tiene como objetivo convertir este departamento en la mejor esquina de América una ambición pretenciosa pero necesaria para su desarrollo económico, social y cultural. Por varias razones es Medellín la ciudad que tendrá la responsabilidad de ser la puerta o el primer contacto con el panorama mundial. Es evidente entonces que hay que terminar de consolidar el Nuevo Centro Internacional acelerando y fortaleciendo el proceso que en la última década ha venido ampliando la oferta de equipamientos para ofrecer los servicios necesarios para implementar esta visión. Se podría establecer que los bordes naturales de esta nueva centralidad son: por el oriente la línea A del Metro, por el norte la línea B del mismo, por el occidente los ramales de la autopista que enmarcan la plaza de toros y una franja importante verde y por el sur la calle 33. El corazón de este nuevo centro en proceso de consolidación es el cruce de la Av. del Ferrocarril y la calle San Juan. Esta intersección que hace unos años pareció estar en la periferia, es hoy el corazón de este nuevo centro, que a su vez es el centro geométrico del área metropolitana. La solución a esta intersección vial ha privilegiado únicamente al vehículo y ha abandonado por completo al peatón y fragmentado tajantemente el tejido urbano en cuatro sectores inconexos.

Por la ubicación de los predios en el cuadrante con más 


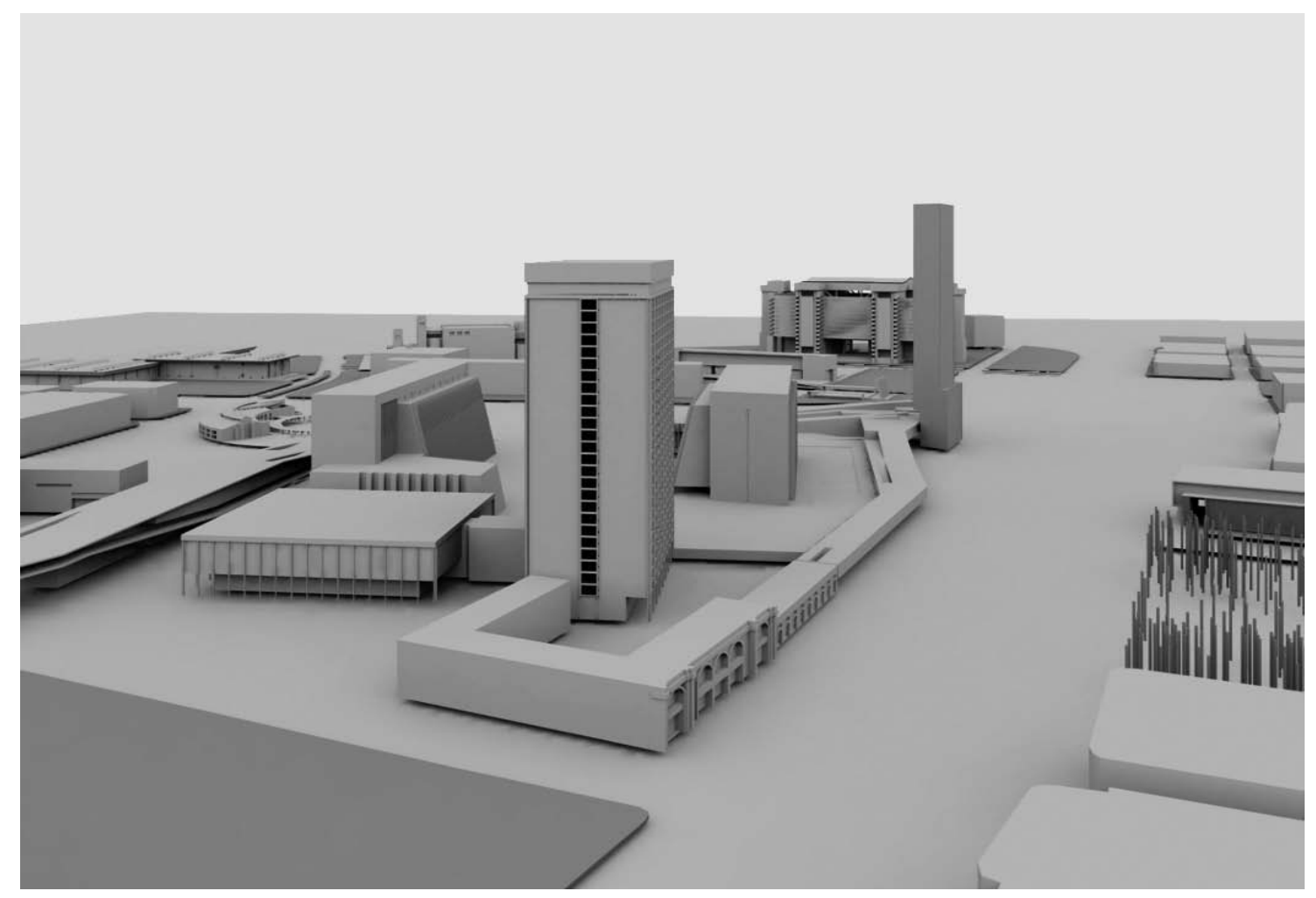

jerarquía y representatividad, por comprometer a La Alpujarra como centro de gobierno departamental y municipal, por la colindancia con importantes infraestructuras, el Concurso Plaza de la Libertad es el verdadero responsable de sentar las bases de una reestructuración definitiva que permita la evolución a corto, mediano y largo plazo de este Nuevo Centro Metropolitano e Internacional.

Para ser factible esta Visión es indispensable resolver primero los problemas que presenta claramente el sector: la inseguridad, la inconexión peatonal, la barrera urbana del basamento del centro administrativo, la desarticulación del transporte masivo (Metro), el desequilibrio ambiental, el déficit actual y la demanda futura de estacionamientos.

Se debe buscar una solución integral que recupere la continuidad del tejido urbano, que incremente los escenarios públicos abiertos y que valore los rasgos territoriales que le den a este Nuevo Centro Metropolitano e Inter- nacional un carácter y una identidad propia, singular y reconocible. Para esto el proyecto debe partir de las condicionantes del contexto y apartarse de modelos urbanos y formales desarrollados en otras ciudades. Los valores arquitectónicos de sus edificios deben reflejar el surgimiento de posibles nuevas topologías surgidas como respuesta directa a las condiciones del lugar, edificios que sólo puedan pertenecer a este sitio específico de Medellín. Dispositivos urbanos de clara vocación utilitaria y expresión formal potente y consecuente con el clima.

Lo particular de cada ciudad es su potencial, es el valor de lo local indispensable para garantizar la supervivencia en la globalidad. Las condiciones climáticas excepcionales del valle han inducido a la búsqueda de generosos espacios abiertos, suelo verde de extensos espacios abiertos (arborizado o no); es una marca de identidad que logró superar el modelo impuesto por los primeros asentamientos coloniales. Debido en gran medida a esta característica urbana, a la ciudad se la ha rotulado le- 


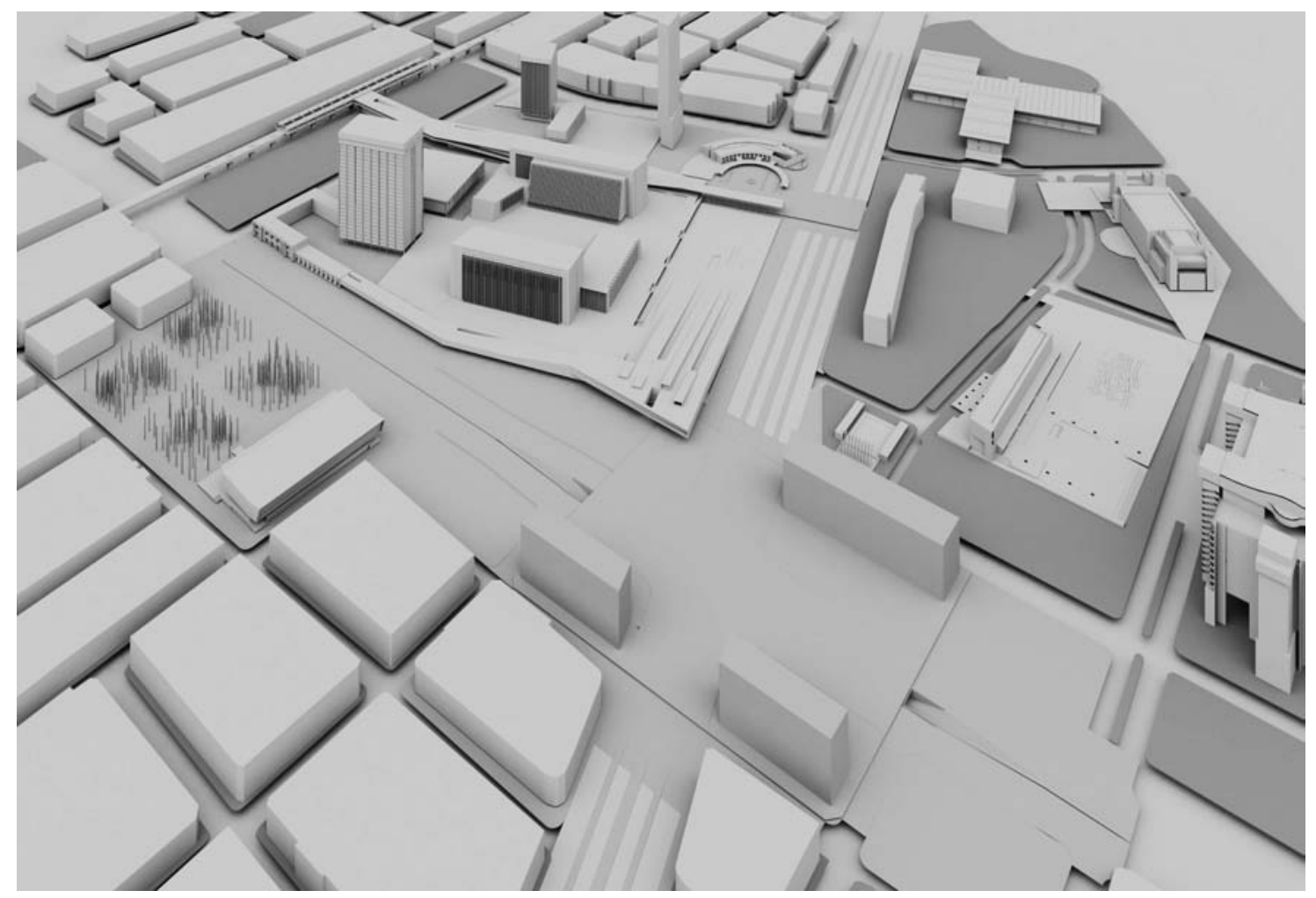

gendariamente como: «Medellín la ciudad de la eterna primavera» 0 "Medellín la ciudad de las flores».

Este cuadrante de manzanas irregulares es un claro vestigio de la noción de ciudad jardín promovida especialmente por el plan maestro de Wiener y Sert y por parte de los trazados de Nel Rodríguez en un sector al occidente del Río Medellín. A esta iniciativa le debemos el legado de los amables parques y bulevares de laureles y especialmente el sector de Suramericana. Esta noción de ciudad abierta y verde es uno de los rasgos urbanos más singulares de Medellín. Estas connotaciones históricas, urbanas y paisajísticas son rasgos distintivos prioritarios en la definición de un Cluster de excelencia para lograr incorporarse a una red de excelencia de ciudades a escala mundial.

Pero para poder convertirse en un destino obligado regional e internacional es imperante dejar atrás la lamentable historia de violencia de Medellín, y para ello sí se requiere de la Libertad ciudadana, pero no una libertad simbólica, buscada prioritariamente en edificios emblemáticos, la verdadera Libertad se da cuando desaparece la segregación y el gueto, se da cuando la ciudad es incluyente, participativa, cuando se privilegia al $85 \%$ de la población que no cuenta con coche con continuidades peatonales, cuando los ciudadanos de todas las edades y aún con limitaciones físicas pueden llegar al corazón de este nuevo centro desde el Metro, protegido por generosas marquesinas y acompañado por galerías de servicios, cuando aparecen verdaderos espacios públicos abiertos que permiten el libre desarrollo de la cultura popular, que privilegian sus fiestas, sus celebraciones colectivas, espacios que son más escenarios que escenografías, lugares para verse y reconocerse y desarrollar una idiosincrasia verdadera.

\section{Datos relevantes del sector}

El desproporcionado nudo vial en el cruce de San Juan y la Av. del Ferrocarril que parece a simple vista una so- 


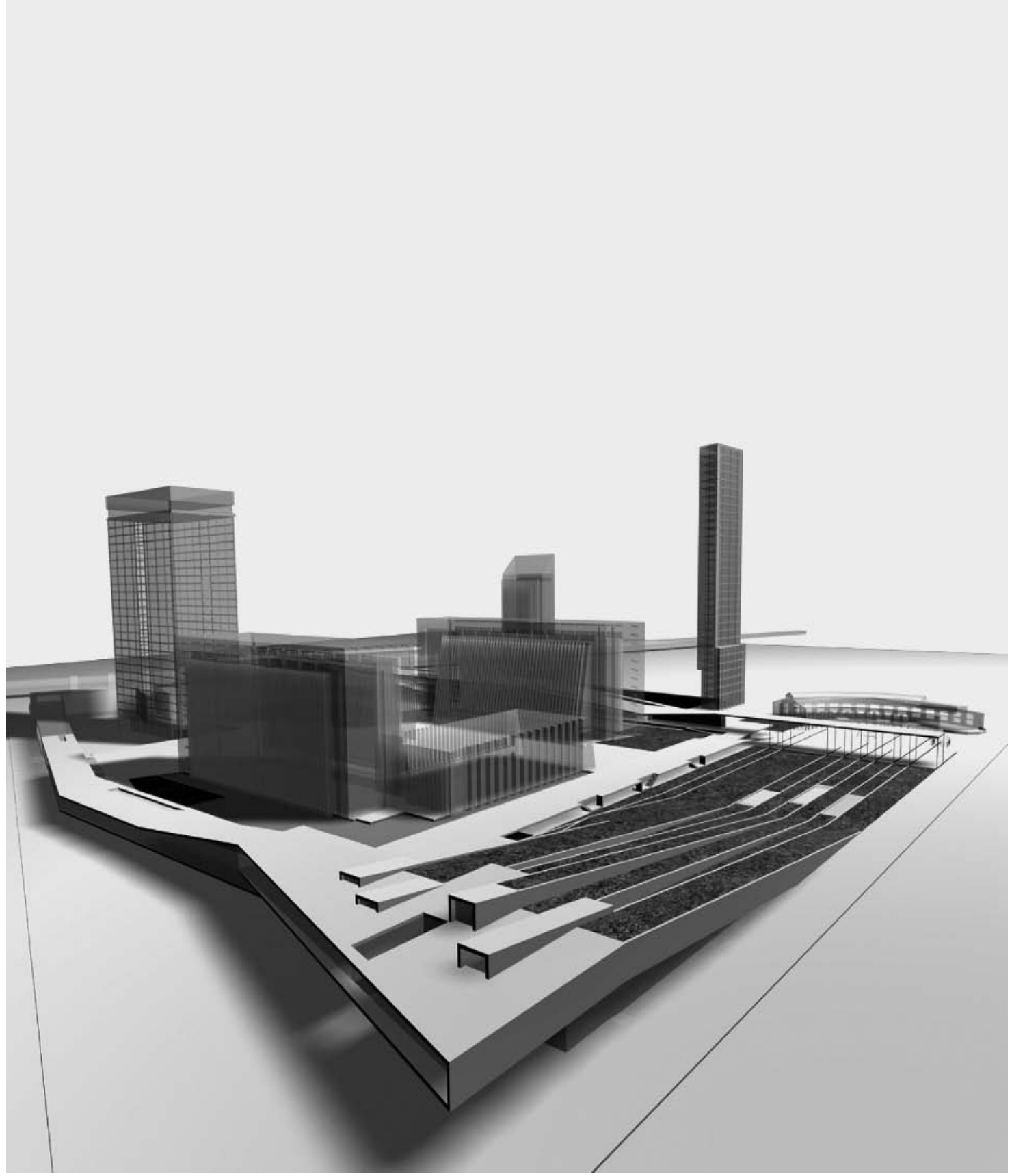

lución necesaria para la vialidad, no es más que una distorsión de los flujos reales de ambas vías. Si se mira con detenimiento se aprecia claramente que aproximadamente el $90 \%$ del trayecto de estas vías está conformado por sólo tres carriles en ambos sentidos, por la escala verdadera de estas vías se les cataloga de secundarias o terciarias en cualquier urbe del mundo y no justifican este desproporcionado nudo vial. Lo que se aprecia en ese sector es un ensanchamiento puntual que ha permitido desencausar los flujos, ocasionando unas turbulencias inoperantes y extremamente contaminantes en todos los sentidos, en especial ambientalmente. En diseño hidráulico es como pasar de una tubería de 3" a una de 9 " en un tramo intermedio corto, para luego terminar en 2", como es el caso de flujos laminares de San Juan.

Lo que ocurre con el deprimido de San Juan es que induce a una velocidad inadecuada para una vía céntrica que se estrangula dos manzanas más adelante rematando en una vía de cuatro carriles en total. El punto y la velocidad con que se sale o entra al deprimido hacen im- posible una conexión peatonal adecuada. Esta hendidura vial anula la conexión peatonal entre Barrio Triste y Alpujarra II y Alpujarra I con Guayaquil y Cisneros. Por su parte los taludes de las rampas del puente de la Av. del Ferrocarril bloquean el paso entre Alpujarra I y II, y entre Barrio Triste y Cisneros y, además, imposibilita la continuidad del bulevar peatonal que corre debajo del viaducto de la línea B del Metro. Ambos casos agravados por el inmenso anillo vial de la glorieta o roundpoint, hoy muy bien revalorizada como centro de ciudad. Lo anterior ilustra claramente que cualquier solución parcial de sendas peatonales, plataformas, túneles o puentes es insuficiente, ingenua y casi siempre desproporcionada. Basta con mirar los actuales puentes peatonales sobre San Juan.

Urbanamente es inaceptable concebir la ejecución de este proyecto y los venideros sin una intervención definitiva como lo es el desmonte de este nudo, que en el día es un elemento de congestión intolerable y de alto riesgo de atropello para el peatón y en la noche es un hoyo 
negro espeluznante donde están dadas todas las condiciones de inseguridad. Basta con atravesarlo peatonalmente a diferentes horas un par de veces para percibir la violencia que genera en todo sentido.

Esta combinación azarosa de foso, muralla y cerco fragmentó la trama urbana en cuatro cuadrantes completamente inconexos que han originado y sostenido un desequilibrio social y de usos muy fuerte que ha acentuado un deterioro físico del sector y ponen en vilo la seguridad del Nuevo Centro Internacional.

\section{Cuadrante 1}

En la magnífica iglesia de Barrio Triste tenían lugar los matrimonios de los ciudadanos ilustres y las ceremonias religiosas más extraordinarias. Hoy este cuadrante reúne un gran numero de cuevas, antros dantescos del bazuco (ripio de la cocaína) de donde han salido muertos algunos de los actores naturales con los que ha trabajado nuestro gran cineasta y antropólogo Víctor Gaviria en sus reveladoras películas. Es por excelencia el mercado negro de autopartes robadas suministradas por los desgüesaderos (talleres clandestinos donde se desarman en minutos los vehículos hurtados). Sus andenes y calles han sido ilegalmente apropiadas y las han convertido en talleres a cielo abierto. Este gueto especializado de baja densidad edilicia constituye el mayor potencial para el desarrollo de un importante programa de vivienda.

\section{Cuadrante 2}

El Hueco, como se le conoce hoy al antiguo núcleo de Guayaquil, es un laberíntico centro comercial urbano, donde el contrabando ilegal de mercaderías surte a aproximadamente 1.500 .000 visitantes diarios. En la esquina sur-occidental de este cuadrante lindando con el nudo vial, se encuentran inadvertidos una serie de inquilinatos habitados por prostitutas que en su mayoría son madres solteras. Sus hijos deambulan permanentemente por las calles todavía ocupadas en parte por recicladores e indigentes. En este cuadrante se negocian los precios de $\mathrm{m}^{2}$ de terreno y de espacio comercial más costosos de la ciudad.

\section{Cuadrante 3}

El cuadrante Alpujarra I, actual centro administrativo, opera como una especie de baluarte rodeado de muros ciegos, rejas, terrazas desiertas y un enjambre de bahías y accesos vehiculares. Después de las 7pm es un verdadero agujero negro totalmente desierto. En su esquina nor-occidental aparece como un apéndice sobreviviente la estación del ferrocarril, cuya galería cercenada parece estar a la espera de una piadosa extensión de su paramento. Esta pequeña estoa es insuficiente para escampar a tanto transeúnte a la espera de un taxi, un autobús, un vehículo particular o de un encuentro y esta responsabilidad ha sido entregada a unos irrisorios paraderos. Las puertas de la nave principal permanecen siempre clausuradas en defensa de la agresiva contaminación vehicular. Este cuadrante contiene zonas aptas para densificar en usos mixtos.

\section{Cuadrante 4}

Alpujarra II concentra los equipamientos culturales y de negocios que presenta la vocación internacional más evidente. En este cuadrante los edificios se acomodan libremente generando grandes vacíos que permiten perspectivas vinculantes entre los mismos, con otros edificios destacados de la ciudad y sobre todo con las montañas estableciendo un vínculo territorial importante, reconocer el valle es un aspecto cultural significativo.

También es fundamental conocer los antecedentes históricos del tramo de San Juan al frente de la estación del ferrocarril entre Carabobo y la Av. del Ferrocarril y lo que ha significado en el desarrollo de eventos culturales públicos. Por mucho tiempo la gran mayoría de las intervenciones públicas de los candidatos a la presidencia de la república tenían lugar aquí, con el candidato hablando desde una de las ventanas de la estación. Calle San Juan servía de plaza para los ciudadanos como también sirvió para el multitudinario y gratuito concierto de Juanes. El escenario se ubicó en la boca de la depresión de la vía y del espectáculos participaron 120.000 espectadores. Sobre los bordes de la vía se arman las graderías temporales para observar el desfile de silleteros, principal 


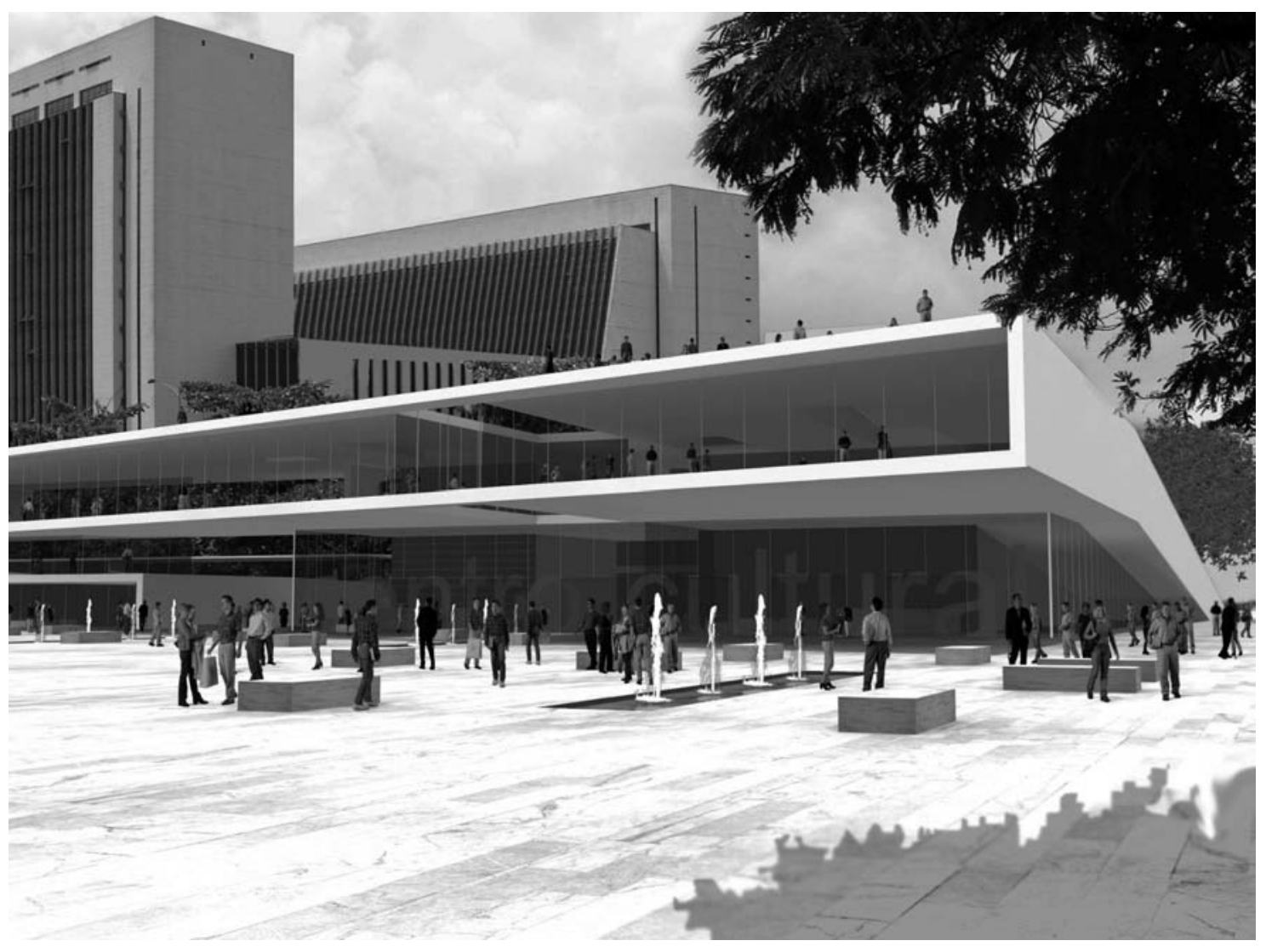

evento de la Fiesta de las Flores. San Juan, recurrentemente e improvisadamente, ha servido como una auténtica plaza; la mayoría de las manifestaciones culturales populares han tenido cita en este lugar.

Después de revisar estos antecedentes no parece muy relevante intentar inscribirse en la competencia abierta entre ciudades americanas, europeas y asiáticas en poseer el Gran Edificio Símbolo, el Rascacielos Universal; cuando además estamos hablando de un edificio que apenas sobrepasa los treinta pisos, un edificio de vivienda del sector del Poblado, o tan alto como su vecino edificio de los juzgados. Hay que reconocer que al menos existe una verdadera conquista tecnológica en edificios que superan los cien pisos y esto puede llevar al reconocimiento de un símbolo tecnológico y de poder.
Buscar un símbolo en el aspecto formal de una edificación es algo bastante subjetivo y riesgoso. Basta con revisar dos experiencias muy cercanas que son parte fundamental de la historia de este lugar y puede ayudar a que no se repitan. En el concurso del Edificio Inteligente EPM, la premisa era crear un nuevo símbolo. En medio del derroche formal importado, buscando novedad, tres de los bordes urbanos de la manzana fueron resueltos con fosos defensivos. Por muchos años estuvo aislado como una fortaleza medieval en medio de manzanas convertidas en estacionamientos.

Actualmente su significado está estrechamente ligado al generoso espacio público que sirve de antesala y que fue cuestionado seriamente por no haber desarrollado un proyecto más denso. Hoy, por fortuna, desde este espa- 
cio a cielo abierto se aprecia La Iglesia de Barrio Triste, el Teatro Metropolitano, el CiC, La Alpujarra, los cerros y las montañas. Ha servido a su vez de parque y de gran escenario público. Hoy incuestionablemente es referente urbano que representa lo público.

El concurso del centro administrativo de la Alpujarra fue también el resultado de la búsqueda del complejo simbólico, hoy después de varias décadas sigue siendo un símbolo vacío de lo público, un complejo edilicio que no ha podido incorporarse a la trama urbana ni al sentimiento ciudadano, por desconocer las necesidades urbanas del lugar que quedaron rezagadas en ese afán de servir de emblema, parece más un símbolo de autocracia y no de democracia. Símbolo y poder casi siempre van de la mano y esto es la verdadera antítesis de la Libertad.

Si se reflexiona con detenimiento es muy poco probable que un edificio de oficinas de dependencias públicas, o un hotel, desarrollado como torre se convierta en un Símbolo de Libertad, con suerte en un emblema del poder o banalmente, en un logo símbolo institucional para fines editoriales. (Siempre operan como recintos privados, puerta, portería, portero, vigilante, documento, etc.) También es bastante improbable que una sumatoria de plazoletas, patios (la tipología del claustro siempre es excluyente del acontecimiento público masivo, la intimidante plaza de la Alpujarra es un patio) y fragmentadas zonas verdes, arborizadas o no, puedan significar una auténtica Plaza o Parque de La Libertad, que necesariamente debe ser actividad pública, es muy diferente a que sólo permitan el ingreso público, los centros comerciales son de ingreso público, pero no son auténticos espacios públicos.

La fragmentación ha sido siempre una estrategia de control, de poder, divídelos y vencerás. Los rótulos en las plantas o en los espacios no es lo que le confiere el carácter a los recintos.

Tampoco parece relevante o justificado incorporar un urbanismo de congestiones y densidades aplicado con frecuencia a ciudades europeas o asiáticas, en la ultima área libre importante en el centro del casco urbano y corazón del nuevo centro internacional; cuando a su alrededor, inscritas en esta nueva centralidad metropolitana, hay un gran número de manzanas de uno y dos pi- sos, muy propensas para ser densificadas. Para qué sacrificar el lote principal del concurso con una ocupación alta incluyendo sótanos, sabiendo que en los costados norte y sur del centro administrativo caben edificios con los programas requeridos por el concurso o en su defecto programas adicionales. El camellón de la alambra es el lote mas apto para construir ya que condensa o compacta el programa institucional, además cuando su subsuelo ya es un sótano de estacionamientos. También hay que ser concientes de que la masa edilicia de La Alpujarra supera la presencia física y simbólica de cualquiera de los edificios propuestos, por el contrario la mayoría crean un choque de lenguajes innecesario. La idea del edificio torre y de la densidad o fragmentación en las propuestas premiadas evidencia un prejuicio que desconoce las verdaderas necesidades del sector y los rasgos paisajísticos mas intrínsecos. En Medellín, y en particular en este sector de La Alpujarra, pareciera tener más significación el rascacielos horizontal el verdadero generador de galerías sombreadas, conectores urbanos escampados. El pasaje comercial horizontal, que orada varias manzanas en el centro de la ciudad, es un distintivo tipológico local. Estas calles cubiertas han demostrado ser una efectiva solución para la protección de la inclemente condición solar de la ciudad y de sus regímenes de Iluvia. Mirar hacia arriba en Medellín encandila, enceguece; en este valle es deseable una mirada horizontal que siempre es retribuida por el verde de las montañas.

Por lo expuesto anteriormente se podría concluir que el proyecto con código JI 25V (séptimo puesto) es la única propuesta que plantea un genuino aporte de verdadero espacio público que contribuye a desarrollar verdaderas libertades ciudadanas y que además se presenta como una evolución programática enraizada al lugar. Es el único proyecto que plantea un recinto con carácter y verdaderamente abierto, que permite evocar lo poético, la ensoñación, que puede dar cabida a una experiencia memorable. La Libertad en este proyecto es un valor real más que retórico.

Bajo una reflexión mas amplia y profunda de la ciudad, parece mucho más coherente y ético, el hecho de que no haya abandonado este símbolo a medio hacer (Centro Administrativo), cuya masa no puede dejar de ser repre- 
sentativa, compitiendo infructuosamente con un nuevo símbolo, proponiendo una operación de reivindicación, una intervención más de complementariedad. El proyecto se inscribe dentro de una visión mas madura, centrada en una recomposición urbana que evita una saturación edilicia y que privilegia la adecuación de un gran parque verde que equilibra la dureza de las plazas vecinas y que se anticipa a mitigar la densificación de este sector en creciente desarrollo. Aplicar estrategias que metamorfosean categóricamente los absurdos y agresivos basamentos de muros ciegos, rejas y terrazas desiertas y que de una vez completen la trunca galería urbana de la Estación del Ferrocarril, evidencia una clara conciencia del lugar y demuestra que es el camino más auténtico para lograr una evolución tipológica del edificio institucional y comercial.

El edificio que nace de la estación es una hibridación entre, arcada, estoa, galería comercial, tribuna, malecón, mirador, lámpara urbana, vestíbulo cubierto, plaza de la sombra, visor urbano, muro de contención...

El edificio que se sitúa sobre el camellón de la alambra es una estación del metro, un puente-rampa urbano, una galería comercial y de servicios, un mirador de la ciudad, una terraza, un basamento habitado, una calle cubierta.. La construcción que alberga el programa cultural y pedagógico (Centro Cultural y Tele Antioquia) sirve de apoyo para la inclinación del parque, una gradería natural, una plataforma de observación; a través de sus aberturas (ojos) se pueden apreciar desde el parque los contenidos al interior del centro cultural y viceversa pudiéndose apreciar el cielo y las montañas. Lo cultural se separa de lo administrativo y constituye un dúo con el parque. Esta conjunción de equipamiento cultural con espacio público abierto ha resultado una estrategia muy eficaz en la recuperación de la cultura pública en Medellín. Su ubicación en la esquina permite que se incorpore al eje cultural Teatro Metropolitano / Museo Interactivo / Centro Cultural de Antioquia / Biblioteca Temática EPM. Esto también garantiza que siempre quede libre de los permanentes cerramientos temporales con vallas acreedor de los edificios administrativos.
El edificio del hotel se presenta como un campanil, como un minarete que, inteligentemente, permite múltiples localizaciones sin poner a riesgo la calidad del espacio publico. Su solución formal, evoca sin duda a una evolución plástica que nos remite a dos de los edificios más emblemáticos y elegantes de la ciudad, el Edificio Colteger y El Banco Cafetero (símbolos de poder) y a su vez en diálogo con La Alpujarra. Su quiebre en altura es un evidente gesto urbano que escampa el acceso y le permite entrelazarse con los otros elementos del proyecto en cualquiera de las ubicaciones (se puede apreciar su aspecto terminado en una pequeña imagen).

Para los operadores hoteleros escoger la ubicación de un nuevo hotel es prioritario y debe ser discutida conjuntamente. La historia reciente de los proyectos Centro de Exposiciones y $\mathrm{CIC}$ demuestra que la iniciativa de edificar un hotel no parte solamente de una decisión urbana o política y por eso se ha abortado en esas ocasiones anteriores y no tiene por qué ser muy diferente a la actual. Sin embargo, si se estudia su ubicación en la esquina nor-occidental, una de las cuatro posibles ubicaciones planteada por la propuesta (donde están todas las torres o edificios palees de los proyectos premiados), se puede imaginar que la plaza cubierta resultaría siendo un magnifico car-lobby o vestíbulo urbano para el hotel, que la inmediatez del acceso principal de Teleanteoquia y El Centro cultural es un gran gancho de promoción. También sería posible que los servicios y restaurantes de sus plantas intermedias tengan acceso por la terraza del parque, contribuyendo a su vitalidad y seguridad. Las vistas principales de las habitaciones quedarían orientadas hacia el parque y la ciudad, balcón privilegiado para las fiestas y eventos culturales más importantes. Su doble acceso por San Juan y por el parque privilegia tanto para su aproximación vehicular y peatonal. Viendo las propuestas formales de los proyectos premiados es evidente que tendría igual reconocimiento como elemento simbólico. Este campanil, por ser un hotel internacional, podría detonar las otras tres torres ubicadas en la plaza propuesta en la intersección de San Juan y Av. Ferrocarril, insinuadas en una de las plantas urbanas y juntas 


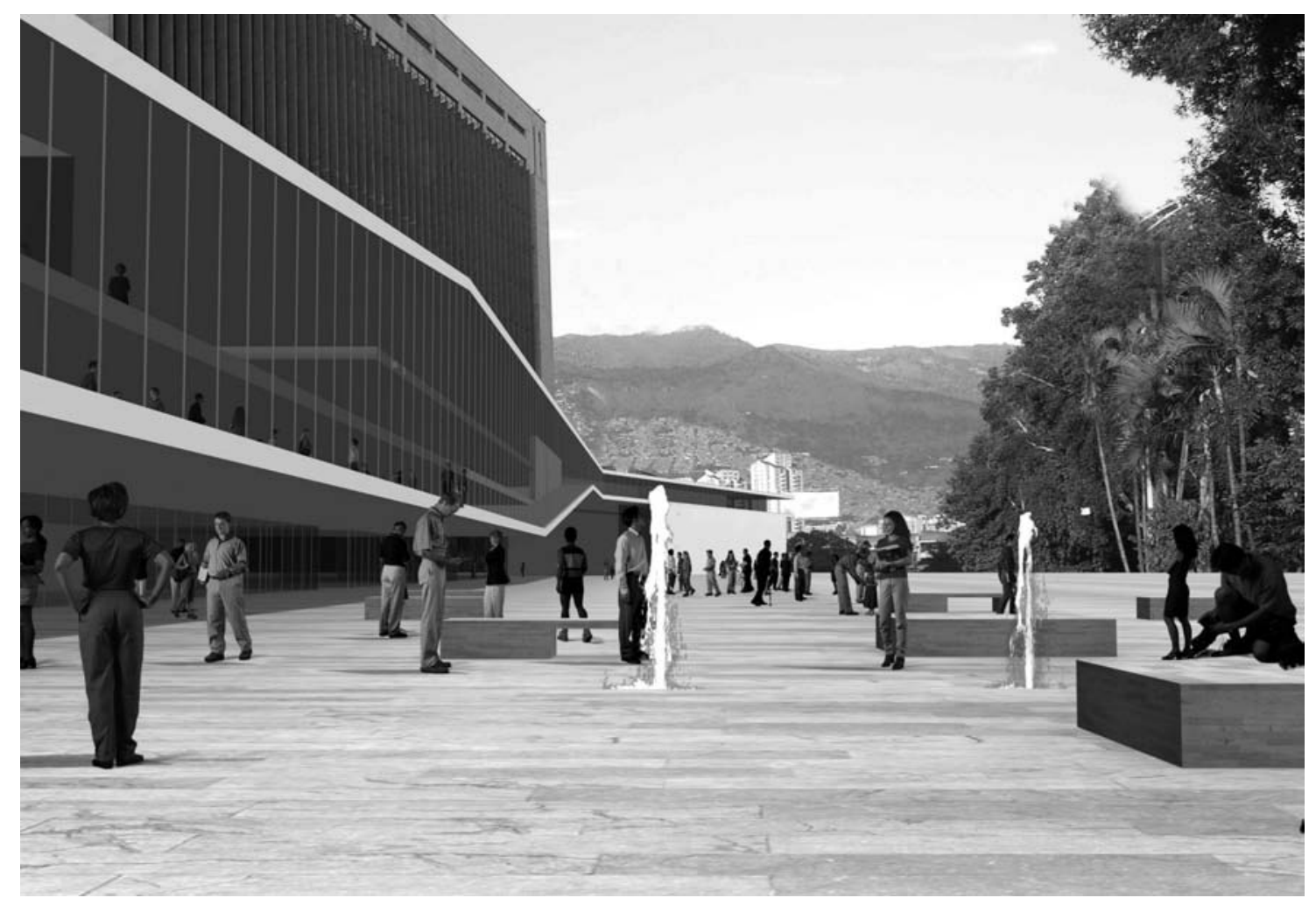

constituir un importante referente urbano de esta nueva centralidad.

Este proyecto denota que el lote, el sitio, el lugar, el territorio y el contexto cultural, son los encargados de proporcionar las claves del lenguaje arquitectónico. Su singularidad y valor plástico radica en que no pudo haber nacido de una imagen a priori, de un vocabulario prestado, sino de las variables topografías, de las geometrías, alturas, flujos y fuerzas del lugar. El proyecto se presenta como una verdadera evolución histórica de una solución contemporánea, no como una revolución o revelación plástica objetual, los edificios y el espacio público fueron pensados y diseñados como verdaderos instrumentos urbanos que permiten libertades en todos los sentidos. No hay duda que Medellín debe densificarse, ser más compacta, sobretodo en su centro, pero no a costa de sacrificar el potencial del último lote institucional de envergadura para desarrollar un auténtico espacio público. Política, económica, social y urbanamente La Ciudad y el Nuevo Centro Metropolitano Internacional precisan de un proyecto como éste, que propone:

1 Replantear seriamente la infraestructura vial que ha roto el tejido urbano, desmantelando el nudo vial San Juan / Av. del Ferrocarril, para lograr una continuidad peatonal efectiva entre los cuatro cuadrantes, algo esencial para el equilibrio social y la seguridad.

2 Adecuar este lugar a su vez para una gran plaza temporal para la celebración de multitud de eventos sin poner en riesgo el deterioro de otros espacios públicos más dotados. 
3 Desarrollar un estacionamiento subterráneo aprovechando el área de lo que hoy ocupa las fundaciones del puente y la actual excavación, que no sólo opere para la gran demanda durante los eventos específicos sino también para la creciente necesidad, esto sería una solución anticipatoria y preventiva, indispensable para la consolidación de este nuevo centro metropolitano.

4 Recuperar los predios de las cuatro esquinas ocupados hoy por segmentos del anillo vial y plazoletas residuales y aplicar una operación de plusvalía que contribuya a financiar todo el proyecto. La noción de que el Estado no sólo gaste sino que invierta es fundamental.

5 Un verdadero proyecto ambiental anulando el foco contaminante principal del sector (nudo vial), liberando el máximo de terreno natural para permitir el libre crecimiento de árboles de escala urbana, facilitando una óptima circulación de aire, de sol y de sombra, permitiendo el máximo de visuales sobre el paisaje del valle (la falta de expresión de la arborización en las planchas presentadas, por hacer muy evidentes los conceptos urbanos, desconcierta en principio ya que la mayoría de las propuestas inundaron los proyectos con árboles y vegetación que en algunos casos puede resultar en una ambientación naturalista ingenua). Cualquier propuesta es susceptible de mejorar el planteamiento de arborización siempre y cuando existan lugares aptos para la siembra.

6 Involucrar al sistema del metro incorporando o extendiendo la estación Alpujarra al corazón del nuevo complejo, utilizando el nuevo edificio institucional como andén y rampa comercial. Esto mejora sustancialmente la accesibilidad pública y contribuye a la democratización del nuevo centro internacional.

7 Remediar de forma definitiva la inoperancia urbana del Centro Administrativo con edificios galerías ubica- dos en los costados norte, occidente y sur del basamento ciego y convierta las terrazas abandonadas en zonas de restaurantes y jardines. Esta recalificación prolonga la vida urbana.

8 Desarrollar un edificio representativo de la ciudad desde los códigos de la misma bajo un concepto de flexibilidad urbana.

Hoy confluyen en la ciudad las políticas de la gobernación y de la alcaldía hacia la ciudad coinciden en que se debe abocar a una ciudad más participativa, incluyente y de grandes libertades. Una ciudad donde la equidad sea posible, donde los derechos de la mayoría prevalezcan. Una ciudad que desarrolle una verdadera cultura urbana de convivencia, donde la seguridad sea la garantía de apertura al mundo. Hoy todas las dependencias técnicas que tienen que ver con la plantación y ejecución de proyectos de ciudad cuentan con arquitectos en los cargos de dirección, Plantación Municipal, Obras Públicas, área metropolitana, El Metro, Secretaria de Transporte, Empresa de Desarrollo Urbano, todos organismos con clara convicción de recuperar la ciudad para el peatón. Lo evidencian los planes, los proyectos y las obras.

Esta coyuntura histórica sin precedentes en la ciudad posibilita la implementación de importantes y significativas readecuaciones a la infraestructura que permitirán un crecimiento y un desarrollo urbano sostenible y equilibrado, donde el peatón y el medio ambiente sean privilegiados, bajo la evolución de modelos urbanos propios. Las ciudades siempre tienen un momento apropiado para implementar grandes cambios, dejarlo pasar es una pérdida invaluable.

Esta reflexión se presenta confiando que los argumentos expuestos ameriten una nueva revisión cuidadosa y más pausada del proyecto al que se hace mención y de las cinco propuestas premiadas. 


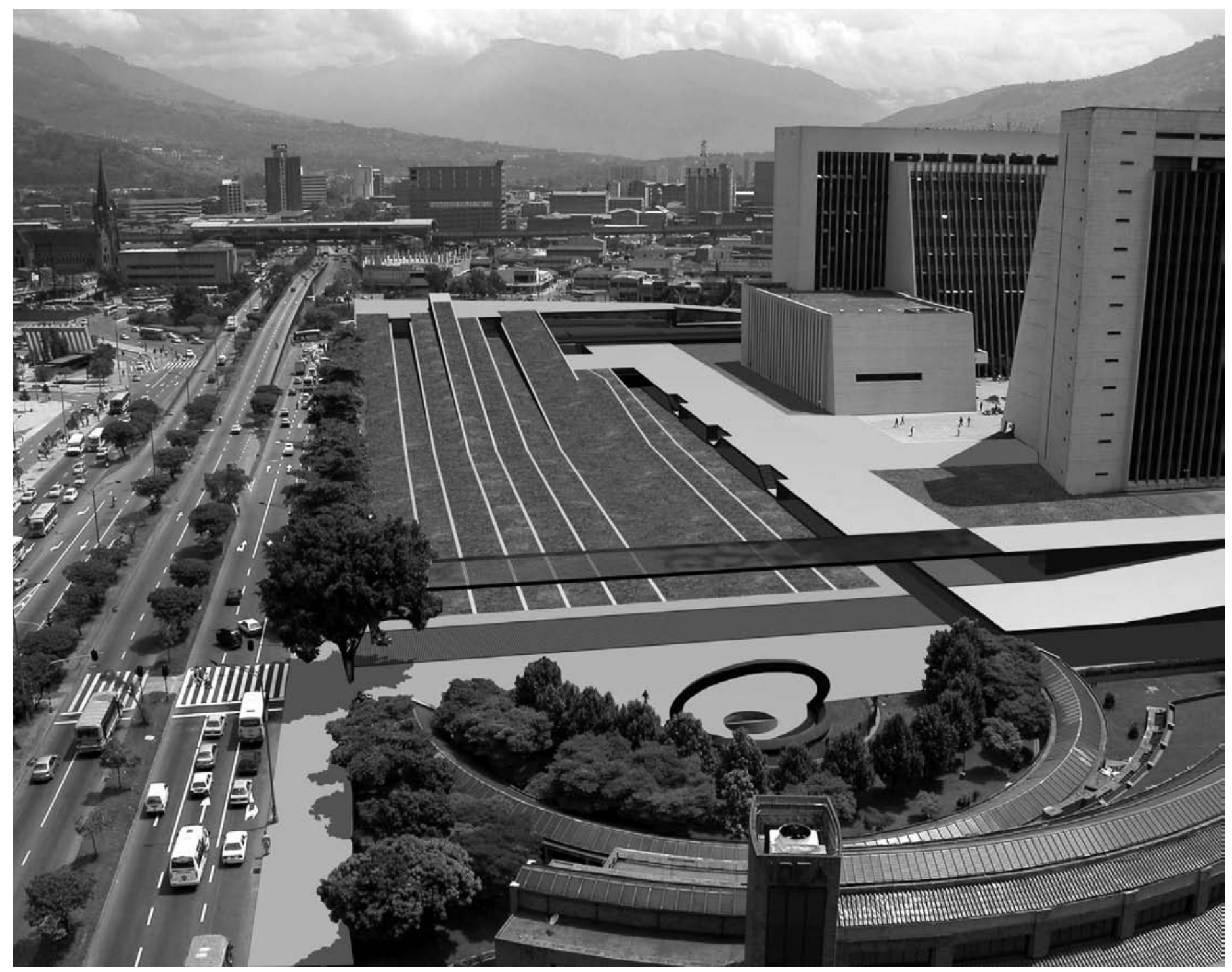

\$a.

Imágenes proporcionadas por el autor. 